\title{
Publisher's Note: Relativistic breather-type solitary waves with linear polarization in cold plasmas
} [Phys. Rev. E 91, 033102 (2015)]

\author{
G. Sánchez-Arriaga, E. Siminos, V. Saxena, and I. Kourakis
}

(Received 5 August 2016; published 10 August 2016)

DOI: 10.1103/PhysRevE.94.029903

This paper was published online on 5 March 2015 with an omission of a byline footnote. G. Sánchez-Arriaga's byline footnote should read as "*Present address: Bioengineering and Aerospace Engineering Department, Universidad Carlos III de Madrid, Madrid, Spain.” The byline footnote has been added as of 5 August 2016. The byline footnote is not present in the printed version of the journal. 